Brit. F. vener. Dis. (1973) 49, 141

\title{
Changing patterns in the organization of the venereal diseases service in the U.S.A.
}

\author{
THE NATIONAL COMMISSION ON THE VENEREAL DISEASES
}

\author{
BRUCE WEBSTER \\ Emeritus Clinical Professor of Medicine, Cornell University Medical College; President, American Social Health \\ Association; Chairman, United States National Commission on the Venereal Diseases
}

At the 22nd General Assembly of the World Health Organization the following resolution was proposed:

'In the opinion of this Assembly all medical and social indications are that the incidence of sexually transmitted diseases will continue to increase from the present serious situation. The Assembly recommends that governments review their venereal disease services and financial provision for those services as a matter of great urgency. It is recommended that National governments and nongovernmental bodies elect panels of experts, medical and nonmedical, to evaluate VD and treponematoses programs. They should take into consideration changing social customs and the experience of the newer methods of disease control. This could result in governments varying legislation and financing control activities which will include research projects.'

Shortly after this, in 1969, the American Social Health Association, in conjunction with the American Medical Association, got together representatives of the various professional organizations in the United States concerned in the treatment of venereal diseases. Out of this grew the concept of a National Commission comprising representatives of public health and private medicine, to make recommendations for the control of the venereal diseases in the United States. Accordingly, in February, 1971, such a Commission was named by the Secretary of Health, Education and Welfare. Represented on this Commission were the American Medical Association, the American Osteopathic Association, the National Medical Association, the Department of Defense, the American Public Health Association, the American Social Health Association, the American College of Obstetricians and Gynecologists, the American Academy of Neurology, the American College of Physicians, the American Academy of Dermatology, the American Urological Association, the American Academy of Family Physicians, the American Venereal Disease Association, the American Academy of Pediatrics, and the Association of American Medical Colleges.
Recognizing that 80 per cent. of cases of venereal disease are treated by private practitioners in the United States, an attempt was made by this Commission to bring together public and private medicine.

The Commission was charged with the following tasks:

(1) To outline ways to improve among medical students and practising physicians the knowledge of, clinical management of, and public responsibility for venereal diseases.

(2) To devise ways to increase the understanding among private physicians of the venereal disease problem and to bring public health and private medicine into a closer working relationship.

(3) To identify broad and specific areas of VD research needs.

(4) To make recommendations for implementing a programme designed to reduce the incidence of venereal disease.

Because of the magnitude of the task, the Commission was divided into five subcommittees:

Research

Education

Private Medicine and Public Health

Operational Research

Implementation

The Commission met as subcommittees and as a whole on numerous occasions. Many consultants were called upon from the Center for Disease Control and from academic medicine.

In the Autumn of 1971 the International Union against the Treponematoses and the World Health Organization sent to the United States an International Travelling Seminar on Venereal Diseases. This group, comprising experts from both the developed and developing countries of the world, spent a month touring the United States and studying the venereal disease problem as it exists here. At the completion of their tour they spent some time in Atlanta at the Center for Disease Control. The National Commission met with them on this occasion and had the benefit of consultation with them. 
Their report, formulated as it was by some of the leading experts in the world, gave the National Commission an excellent picture of an outsider's view of our venereal disease control situation, as evaluated by impartial experts. The report of this Travelling Seminar was of great value to the National Commission in formulating our final recommendations.

The Report of the National Commission was submitted to the Secretary of Health, Education and Welfare on April 4, 1972. The National Commission made the following recommendations:

\section{RESEARCH}

(1) That an enlarged nucleus of capable scientists both inside and outside the Department of Health, Education and Welfare be recruited for active engagement in venereal disease research.

(2) That studies be vigorously pursued for the development of vaccines for syphilis and gonorrhoea, it being fully realized that few infectious diseases have been brought under effective control without suitable vaccines.

(3) That studies be pursued for the development of safe and effective topical or systemic prophylaxis for venereal diseases.

(4) That detailed studies of the microbiology and immunology of uncomplicated gonorrhoea, the complications of gonorrhoea, and the pathogenesis of gonococcal infection be intensified.

(5) That investigations designed to improve diagnostic methods, including both immunological procedures and culture, be more vigorously prosecuted.

(6) That research into the effectiveness of current control programmes be undertaken.

(7) That a group of investigators with expertise in sexually transmitted diseases other than syphilis and gonorrhoea be developed and an appropriate unit with responsibilities for these diseases be established at the Center for Disease Control.

(8) That the Federal Government increase its support for the study of human behaviour and its relationship to the venereal diseases, including attitudes toward education and prophylaxis, as well as studies to determine to what extent the present methods of venereal disease case reporting and contact tracing may deter patients from seeking treatment and discourage physicians from cooperating.

(9) That an advisory council on venereal diseases with appropriate governmental and nongovernmental membership be established to make recommendations to the Assistant Secretary for Health and Scientific Affairs of the Department of Health, Education and Welfare for the implementation of the research and control programs designed to reduce the incidence of the venereal diseases.

\section{EDUCATION}

(10) That a strenuous effort should be made to reinstitute the teaching of venereology in medical schools and schools of public health and that this teaching be subsidized in each school by a federal grant of $\$ 20,000$ to $\$ 30,000$ per year.

(11) That education about the venereal diseases be introduced in the curriculum of public, parochial, and private schools no later than in the seventh grade as a part of a basic education in health sciences.

(12) That the Federal Government initiate and support a programme of public education and information about the venereal diseases similar to that of the National Clearinghouse on Smoking and Health.

\section{IMPLEMENTATION}

(13) That the Federal Government make changes in existing laws and regulations which would $(a)$ authorize, as under Public Law 91-623, the Department of Health, Education and Welfare to assign commissioned officers to State and local areas for venereal disease control activities, $(b)$ require that all health care facilities, which provide general medical services or more limited health care services, make available diagnostic testing for the venereal diseases and treatment for these diseases to those patients found to be infected if the programmes are to be considered eligible for federal sponsorship; and $(c)$ require that, in order to be eligible for federal support, facilities or programmes which provide treatment for venereal disease patients use adequate treatment schedules which have been demonstrated to be economical, safe, and effective.

(14) That federal, state, and local governments make a strenuous effort to improve the organization and management of venereal disease clinics, to upgrade the quality of care rendered in these clinics, and to provide facilities which allow a maintenance of reasonable standards of privacy and dignity for patients.

(15) That medical specialty groups establish standing committees on the venereal diseases with mechanisms for communication among and joint action by these committees.

(16) That each state and, where appropriate, each local government, establish permanent commissions or similar advisory groups with representation from medical and other professional health groups, legislative bodies, and the general public to advise the responsible health officials on their venereal disease control programme; that State and appropriate local medical societies establish standing committees with similar responsibilities; and that special emphasis be placed on attempts to promote the reporting of venereal diseases by practising physicians and to encourage epidemiological follow-up.

(17) That, to reduce the incidence of venereal disease, known control techniques, including casefinding and public education, be fully employed on a nationwide basis, and such programmes be funded primarily through federal project grants.

(18) That, for all elements of the venereal disease control efforts, the Federal Government appropriate and expend through the Department of Health, Education, and Welfare in fiscal year 1973 a total of $\$ 46,150,000$, 
this sum increasing to $\$ 68,035,000$ in fiscal year 1977 .

What will be the impact of such a Commission Report? It would appear that already increased interest in research into the fundamental aspects of the gonococcus and Treponema pallidum has been stimulated. The National Institute of Health is issuing, at regular intervals, bulletins on the status of this research. These are being distributed to the immunologists and microbiologists throughout the country. Several grants for basic research have already been made. There is an increased amount of interest in the relationship between the behavioural sciences and venereal disease control in the United States. In the opinion of many, this is a fertile field for investigation. We must know more about the attitude of the high risk groups toward the methods of control which we are employing. Will they accept them?

During the past 2 months Federal funding for venereal disease control has been increased from 16 to 31 million dollars for the fiscal year 1972. Bills are now being formulated in the congress and senate of the United States, intended to provide funding for the recommendations of the National Commission. Whether or not these become a reality will depend to a large extent on whether or not the general public demands them. The press, radio, and television are already doing their part towards educating the public on the seriousness of the present epidemic of the venereal diseases. It is hoped that this will be reflected in political action.

As pointed out both by the report of the National Commission on the Venereal Diseases and by the WHO/IUVDT Travelling Seminar, there is a critical shortage of medical manpower interested in venereal disease control in the United States. Accordingly, we have strongly recommended that teaching and training grants be provided for the medical schools and schools of public health, in an effort to reintroduce this subject. We have urged that venereal disease clinics be put back into university hospitals. The medical student of today is our hope for future control.

Several states have formed, or are in the process of forming, venereal disease control task forces to evaluate the problem in their particular states. This, in itself, is a big step forward.

In summary, this is a programme which has been outlined for the control of the venereal diseases in the United States. If it can be funded, and properly activated, it should stem the rising tide of the venereal disease epidemic. If this does happen, it is important for us to remember that provision must be made for continuing or ongoing control, if we are going to maintain any progress which we may make. 